\title{
Can Paleoceanographic Tracers Constrain Meridional Circulation Rates?
}

\section{Citation}

Huybers, Peter J., Geoffrey Gebbie, and Olivier Marchal. 2007. Can paleoceanographic tracers constrain meridional circulation rates? Journal of Physical Oceonography 37(2): 394-407.

\section{Published Version}

http://dx.doi.org/10.1175/JP03018.1

\section{Permanent link}

http://nrs.harvard.edu/urn-3:HUL.InstRepos:3383440

\section{Terms of Use}

This article was downloaded from Harvard University's DASH repository, and is made available under the terms and conditions applicable to Other Posted Material, as set forth at http:// nrs.harvard.edu/urn-3:HUL.InstRepos:dash.current.terms-of-use\#LAA

\section{Share Your Story}

The Harvard community has made this article openly available.

Please share how this access benefits you. Submit a story.

Accessibility 


\title{
Can Paleoceanographic Tracers Constrain Meridional Circulation Rates?
}

\author{
Peter Huybers* \\ Woods Hole Oceanographic Institution, Woods Hole, Massachusetts \\ GeOFFREy GebBIE \\ Harvard University, Cambridge, Massachusetts \\ Olivier Marchal \\ Woods Hole Oceanographic Institution, Woods Hole, Massachusetts
}

(Manuscript received 8 August 2005, in final form 12 January 2006)

\begin{abstract}
The ability of paleoceanographic tracers to constrain rates of transport is examined using an inverse method to combine idealized observations with a geostrophic model. Considered are the spatial distribution, accuracy, and types of tracers required to constrain changes in meridional transport within an idealized single-hemisphere basin. Measurements of density and radioactive tracers each act to constrain rates of transport. Conservative tracers, while not of themselves able to inform regarding rates of transport, improve constraints when coupled with density or radioactive observations. It is found that the tracer data would require an accuracy one order of magnitude better than is presently available for paleo-observations to conclusively rule out factor-of- 2 changes in meridional transport, even when assumed available over the entire model domain. When data are available only at the margins and bottom of the model, radiocarbon is unable to constrain transport while density remains effective only when a reference velocity level is assumed. The difficulty in constraining the circulation in this idealized model indicates that placing firm bounds on past meridional transport rates will prove challenging.
\end{abstract}

\section{Introduction}

The marine sediment record is one of the few means by which to extend the relatively short record of instrumental oceanographic observation. In particular, sediment data may permit testing of the ocean's role in past climate change (e.g., Clark et al. 2002). However, the accuracy, type, and location of sediment data required to conclusively determine past ocean circulation states remains largely unknown.

The most common proxies of the ocean paleocirculations are the stable carbon isotopic ratio $\left({ }^{13} \mathrm{C} /{ }^{12} \mathrm{C}\right.$, usually expressed as $\delta^{13} \mathrm{C}$ ) and the cadmium-to-calcium $(\mathrm{Cd} / \mathrm{Ca})$ ratio of the carbonate shells of bottomdwelling animals (benthic foraminifera) buried in marine sediments. The $\delta^{13} \mathrm{C}$ and $\mathrm{Cd} / \mathrm{Ca}$ ratios of benthic

\footnotetext{
* Current affiliation: Department of Earth and Planetary Sciences, Harvard University, Cambridge, Massachusetts.

Corresponding author address: Peter Huybers, Department of Earth and Planetary Sciences, Harvard University, 20 Oxford St., Cambridge, MA 02138.

E-mail: phuybers@fas.harvard.edu
}

shells obtained from surface sediments have been shown to reflect, respectively, the $\delta^{13} \mathrm{C}$ of dissolved inorganic carbon and the $\mathrm{Cd}$ content of bottom waters (e.g., Duplessy et al. 1984; Boyle 1988, 1992), which both covary with the nutrient content (e.g., dissolved phosphorus) of the bottom waters (Kroopnick 1985). High-density water masses that originate from high latitudes and fill the abyssal ocean today have distinct isotopic and chemical signatures. Most notably, North Atlantic Deep Water (NADW) has relatively high $\delta^{13} \mathrm{C}$ and low $\mathrm{Cd} / \mathrm{Ca}$ when compared with Antarctic Bottom Water (AABW) (Kroopnick 1985; Boyle 1988). Thus, benthic data from Atlantic Ocean sediments can provide information about the proportion of waters of northern and southern origins.

During the Last Glacial Maximum (LGM, near 21 kyr B.P.), North Atlantic benthic data indicate nutrient enrichment in deep water (low $\delta^{13} \mathrm{C}$, high $\mathrm{Cd} / \mathrm{Ca}$ ) and nutrient depletion in intermediate water (high $\delta^{13} \mathrm{C}$, low $\mathrm{Cd} / \mathrm{Ca}$ ) (for reviews see Boyle 1992; Marchitto et al. 2002). The prevailing interpretation of the LGM $\delta^{13} \mathrm{C}$ and $\mathrm{Cd} / \mathrm{Ca}$ distributions is that nutrient-poor NADW shoaled and that a nutrient-rich AABW filled the deep Atlantic (e.g., Duplessy et al. 1988; Curry et al.

DOI: $10.1175 / J P O 3018.1$

(C) 2007 American Meteorological Society 
1988; Boyle 1992; Marchitto et al. 1998; Curry and Oppo 2005). This view, however, has not gone unchallenged. Alternative hypotheses are that the nutrient content of NADW was different during the LGM (e.g., Mix and Fairbanks 1985; Legrand and Wunsch 1995; Matsumoto et al. 2001) or that NADW continued to "form" with nearly its current composition, but filled the depths of the northeastern Atlantic (Sarnthein et al. 1994).

Even if one accepts the prevailing interpretation of the data, the cause of the implied circulation changes still remains unclear. It was proposed that the inferred higher volume of glacial AABW was a passive response to the reduced production of glacial NADW in the North Atlantic, which may have occurred as a result of surface freshening (Boyle and Keigwin 1987). Alternative mechanisms possibly associated with changes in the distribution of NADW are wind stresses in the Southern Ocean (Toggweiler and Samuels 1998) and changes in vertical mixing (Munk and Wunsch 1998). The energy sources for vertical mixing are primarily provided by the winds and tides (e.g., Wunsch and Ferrari 2004), and these are expected to be larger during periods characterized by high wind stresses and low global sea level. From this perspective, a reduced circulation rate during the LGM would be surprising (Wunsch 2003).

In a pioneering work Legrand and Wunsch (1995, hereafter LW95) used an inverse method to combine paleoceanographic data and a model of the deep North Atlantic circulation. LW95 employed a model having a simplified representation of the physics of the ocean circulation (geostrophic model). Two different types of paleodata were used: benthic $\delta^{18} \mathrm{O}\left({ }^{18} \mathrm{O} /{ }^{16} \mathrm{O}\right.$ ratio $)$ and benthic $\delta^{13} \mathrm{C}$. The $\delta^{18} \mathrm{O}$ of a carbonate shell depends on the temperature and the $\delta^{18} \mathrm{O}$ of the water in which it was precipitated. LW95 used carbonate $\delta^{18} \mathrm{O}$ data to constrain bottom-water densities, assuming that $\delta^{18} \mathrm{O}$ gradients primarily reflect temperature gradients and thus constrain density gradients. Here, $\delta^{13} \mathrm{C}$ was considered as a conservative tracer-omitting the effect of organic matter remineralization on $\delta^{13} \mathrm{C}$ (oxidation of organic matter, which has a relatively low ${ }^{13} \mathrm{C} /{ }^{12} \mathrm{C}$ ratio, tends to reduce the $\delta^{13} \mathrm{C}$ of ambient dissolved inorganic carbon).

The study of LW95 comprised two separate components. First, they combined their model with temperature, salinity, and dissolved phosphorous data to produce a modern reference circulation. Second, they conducted two inversions to evaluate whether the glacial benthic $\delta^{18} \mathrm{O}$ and $\delta^{13} \mathrm{C}$ data are consistent with (i) the reference circulation or (ii) another circulation characterized by a southward NADW flux reduced by half. They concluded that these data are consistent with both circulations. More generally, LW95 concluded that conservative tracers are unable to constrain rates of circulation, only informing regarding the standing stock of water, and that a "clock" as provided by geostrophy or a radioactive tracer is needed to constrain rates of flow.

Examples of paleoceanographic observations able to clock the rate of flow include measurements of the difference in ${ }^{14} \mathrm{C}$ radioactivity between surface and bottom-dwelling foraminifera species (e.g., Adkins and Boyle 1997; Sikes et al. 2000; Keigwin 2004). Another tracer that may possibly inform about rates of flow in past oceans is the ${ }^{231} \mathrm{~Pa} /{ }^{230} \mathrm{Th}$ ratio of the bulk sediment (Yu et al. 1996; Marchal et al. 2000; McManus et al. 2004). Constraints on past vertical shear have been inferred by estimating horizontal density gradients in the Florida Straits using an empirical relationship between benthic $\delta^{18} \mathrm{O}$ and water density (Lynch-Stieglitz et al. 1999). This method has also been applied to explore past changes in vertical shear in the South Atlantic (Lynch-Stieglitz et al. 2006; Gebbie and Huybers 2006).

Winguth et al. (2000) used the adjoint of an ocean general circulation model to bring it into better consistency with $\mathrm{LGM} \delta^{13} \mathrm{C}$ and $\mathrm{Cd} / \mathrm{Ca}$ data. This model was more complete than that of LW95, including the processes of organic matter production in the surface layers and remineralization at depth. Remineralization tends to decrease the $\delta^{13} \mathrm{C}$ of the dissolved inorganic carbon with time, thus providing a clock for the circulation rate, but one whose accuracy depends on poorly constrained rates of remineralization. Winguth et al. (2000) found that a shoaling and reduction in the flux of NADW reduces model-data misfits by $25 \%$, which is consistent with the prevailing interpretation of $\delta^{13} \mathrm{C}$ and $\mathrm{Cd} / \mathrm{Ca}$ records discussed above. Note, however, that model adjustments were only permitted to surface salinity values, and it is unknown whether a $25 \%$ reduction in the model-data misfit could also be obtained through adjustment of other model parameters without similar consequences for the flux of NADW.

In some sense LW95 and Winguth et al. (2000) obtained similar results: the paleodata are consistent with a shoaling and reduction in the flux of NADW. The primary difference between these studies, however, is that LW95 also showed that the paleodata are consistent with the modern circulation and thus the data could not distinguish between changes in the meridional circulation. Here, we address the question of what paleodata are required to show that certain hypothetical circulation states are inconsistent with the data. More specifically, we consider the accuracy and distribution of conservative, radioactive, and dynamically active classes of tracers required to bound rates of meridional transport within a factor of 2 . 


\section{Inverse method}

To explore the observational requirements for bounding the meridional transport, we use an inverse method to combine a geostrophic circulation model with idealized observations. The circulation model is first described. Then a schematic reference state of the model is presented from which idealized tracer "observations" are sampled.

\section{a. Circulation model}

The model generally follows LW95, except that we use a more idealized basin. The hypothetical ocean basin has a flat bottom and vertical walls and extends from $10^{\circ}$ to $50^{\circ} \mathrm{N}$ in latitude, from $0^{\circ}$ to $35^{\circ}$ in longitude, and from 1 to $4 \mathrm{~km}$ in depth. The domain is divided into $10^{\circ} \times 10^{\circ} \times 1 \mathrm{~km}$ boxes except along the western boundary where boxes are $5^{\circ}$ in longitude, giving 48 boxes in total. Boundary transport is only allowed through the north, south, and top surfaces of the domain. Inversions using a 100-box model (not shown) lead to conclusions consistent with those presented here.

The circulation model is based on the following approximate dynamical constraints.

Conservation of mass is expressed as

$$
\frac{\partial u}{\partial x}+\frac{\partial v}{\partial y}+\frac{\partial w}{\partial z}=\epsilon_{m}
$$

where $\epsilon_{m}$ represents the imbalance. The thermal wind relations are

$$
\begin{gathered}
\frac{\partial u}{\partial z}=\frac{g}{f \rho_{0}} \frac{\partial \rho}{\partial y}+\epsilon_{u} \quad \text { and } \\
\frac{\partial v}{\partial z}=-\frac{g}{f \rho_{0}} \frac{\partial \rho}{\partial x}+\epsilon_{v} .
\end{gathered}
$$

Here, $g$ is the acceleration due to gravity, $f$ is the Coriolis parameter, and $\rho_{0}=1025 \mathrm{~kg} \mathrm{~m}^{-3}$ is a reference density. The planetary vorticity balance is

$$
\frac{\partial w}{\partial z}=\frac{\beta}{f} v+\epsilon_{s}
$$

with $\beta=\partial f / \partial y$. A vorticity balance is not imposed along the western boundary where higher-order dynamical effects are expected to be important. The density equation is

$$
\frac{\partial}{\partial x} u \rho^{\prime}+\frac{\partial}{\partial y} v \rho^{\prime}+\frac{\partial}{\partial z} w \rho^{\prime}=\epsilon_{\rho},
$$

where the density anomaly, $\rho^{\prime}=\rho-\rho_{o}$, is used in place of $\rho$ to minimize sources or sinks of density owing to imbalances in the conservation of the mass term (see Ganachaud 2003).

Conservation equations are also written for conservative and radioactive tracers, which are nominally identified with $\delta^{13} \mathrm{C}$ and $\Delta^{14} \mathrm{C}$, respectively. The conservation of $\delta^{13} \mathrm{C}$ is

$$
\frac{\partial}{\partial x} u \delta^{13} \mathrm{C}+\frac{\partial}{\partial y} v \delta^{13} \mathrm{C}+\frac{\partial}{\partial z} w \delta^{13} \mathrm{C}=\epsilon_{13},
$$

where the effect of organic matter remineralization on $\delta^{13} \mathrm{C}$ is omitted. Note that $\delta^{13} \mathrm{C}$ is a unitless quantity typically expressed in parts per thousand (i.e., \%o). The concentration of radiocarbon, ${ }^{14} \mathrm{C}$, is expressed as

$$
\frac{\partial}{\partial x} u^{14} \mathrm{C}+\frac{\partial}{\partial y} v^{14} \mathrm{C}+\frac{\partial}{\partial z} w^{14} \mathrm{C}=-\lambda^{14} \mathrm{C}+\epsilon_{14},
$$

where $\lambda=(\ln 2) /(5730 \mathrm{yr})$ is the radiocarbon decay constant. The ${ }^{14} \mathrm{C}$ concentrations are conventionally expressed as $\Delta^{14} \mathrm{C}$, a quantity that accounts for fractionation effects (e.g., Broecker and Peng 1982). Because of the requirement for decay to be proportional to the concentration, $\Delta^{14} \mathrm{C}$ is not directly represented in the model. Instead, following Toggweiler et al. (1989), the ${ }^{14} \mathrm{C}$ concentrations are modeled using a scale between zero and one and then subsequently converted into the conventional notation using the relationship $\Delta^{14} \mathrm{C}=$ $\left({ }^{14} \mathrm{C}-1\right) \times 1000$. Use of ${ }^{14} \mathrm{C}$ values directly, as opposed to converting measurements into "ventilation ages," circumvents problems in interpreting the physical significance of such ages (see Wunsch 2002).

After discretizing to the model grid and linearizing the model equations (see Legrand 1995), the dynamical constraints can be concisely stated in matrix form as

$$
\mathbf{A x}=\mathbf{b}+\epsilon .
$$

Each term in Eq. (8) is discussed separately.

The $\mathbf{x}$ term is the state vector and has 600 entries corresponding to the tracer and transport values for each box. Transports are defined on box faces while tracers are defined at corners. Also included as part of the state vector is the northward volume transport integrated between $0^{\circ}$ and $35^{\circ}$ of longitude and 1 and 4 $\mathrm{km}$ of depth at each latitude, denoted $F_{\text {tot }}$, and the transport integrated over a smaller domain between $5^{\circ}$ and $35^{\circ}$ of longitude and 2 and $4 \mathrm{~km}$ of depth, denoted as $F_{\text {deep }}$. These integrated fluxes prove convenient for controlling the gross behavior of the model and add 10 terms ( 2 for each latitude) to the state vector.

The next term discussed in Eq. (8) is the matrix $\mathbf{A}$, representing the collection of constraints on the state. Each column corresponds to an element in the state vector, and each row represents a constraint on how different elements of the state vector interrelate. There are 372 constraints in total. Conservation equations involving the product of a tracer times velocity are nonlinear and thus require an iterative procedure to solve (see Mercier 1989). At each step of the iteration, the 
conservation constraints in $\mathbf{A}$ are relinearized around the current model state. The vector $\mathbf{b}$ balances the result of $\mathbf{A}$ operating on $\mathbf{x}$ up to the errors in the observations and model.

The final term in Eq. (8) is $\epsilon$, a vector representing the imbalances associated with each dynamical constraint. Imbalances are expected to be zero mean, $\langle\epsilon\rangle=$ 0 , with an error covariance matrix $\mathbf{Q}=\left\langle\epsilon \epsilon^{\mathrm{T}}\right\rangle$. Here, $\mathrm{T}$ indicates the transpose and angle brackets indicate the expectation. Also assigned is a prior estimate of the state, $\mathbf{x}_{o}$, with an error covariance matrix $\mathbf{P}=\langle(\mathbf{x}-$ $\left.\left.\mathbf{x}_{o}\right)\left(\mathbf{x}-\mathbf{x}_{o}\right)^{\mathrm{T}}\right\rangle$. For elements of the state vector directly constrained by observations, the prior estimate is the observation itself. Actual values for $\mathbf{x}_{o}$ and the covariance matrices are discussed in section $2 \mathrm{~b}$.

The information contained in the observations and the dynamical constraints are combined according to their respective uncertainties and can be stated as the minimization of a cost function,

$$
J=\left(\mathbf{x}-\mathbf{x}_{o}\right)^{\mathrm{T}} \mathbf{P}^{-1}\left(\mathbf{x}-\mathbf{x}_{o}\right)+(\mathbf{A} \mathbf{x}-\mathbf{b})^{\mathrm{T}} \mathbf{Q}^{-1}(\mathbf{A} \mathbf{x}-\mathbf{b}) .
$$

The first and second terms in on the right-hand side are associated with the observational (or prior estimate) cost, $J_{o}$, and the dynamical cost, $J_{d}$, respectively. Dynamical constraints are written in units of Sverdrups $\left(\mathrm{Sv} \equiv 10^{6} \mathrm{~m}^{3} \mathrm{~s}^{-1}\right)$. The nonlinear conservation equations are also expressed in units of Sverdrups as the tracers are normalized to be unitless and have mean values near 1 . In the following discussion, the square roots of the diagonal entries for the $\mathbf{P}$ and $\mathbf{Q}$ matrices are referred to as observational and dynamical uncertainties, respectively, indicated by $\pm 1 \mathrm{~Sv}$, for example.

We make the simplifying assumption that no covariance exists between the different elements of $\mathbf{x}$ or rows of $\mathbf{A}$. That is, $\mathbf{P}$ and $\mathbf{Q}$ are taken as diagonal and $J$ is a sum of the squares. Omitting the covariance terms is partly justified in that nearly perfect mass conservation will be specified in the following inversions, thus keeping the covariance between mass [Eq. (1)] and tracer imbalances [Eqs. (5)-(7)] small.

\section{b. Reference model state}

A reference state is generated in a two-step approach. In the first step, a southward meridional transport of $F_{\text {tot }}=-15 \pm 0.1 \mathrm{~Sv}$ is prescribed at each latitude. A further transport of $F_{\text {deep }}=5 \pm 1 \mathrm{~Sv}$ of northward transport is prescribed east of the boundary current between 2 and $4 \mathrm{~km}$. The individual transports through each box face are loosely constrained at $0 \pm 20$, $0 \pm 15$, and $0 \pm 10 \mathrm{~Sv}$ in the upper, middle, and deepest layers, respectively (for vertical velocities this corre- sponds to the upper face). These large transport uncertainties permit the model to freely adjust toward a circulation consistent with the constraints.

The values of $\delta^{13} \mathrm{C}$ and $\Delta^{14} \mathrm{C}$ are everywhere assigned to be zero and, therefore, do not contribute to the cost [see Eqs. (6) and (7)]. Density anomalies, $\rho^{\prime}$, are also initially assumed to be $0 \pm 1 \mathrm{~kg} \mathrm{~m}^{-3}$ everywhere, but, unlike the passive tracers, will require adjustment to be in dynamical balance with the transports [Eqs. (2) and (3)]. Placing a finite uncertainty on the state vector is necessary to prevent values from increasing without bound.

Dynamical constraints are assigned very small uncertainties of $\pm 0.01 \mathrm{~Sv}$, which are overly optimistic. More realistic dynamical uncertainties would be on the order of 1 Sv (see Wunsch 1996; Ganachaud 2003), but for the present idealized study this provides the best chance for tracers to constrain the circulation. For example, smaller uncertainty in the thermal wind constraint more tightly couples the density gradients to the vertical shear.

It is useful for the reference state to almost perfectly satisfy the dynamical constraints; otherwise, separating the changes in the circulation caused by dynamical imbalances from the changes caused by the tracer observations becomes difficult. The minimization of the dynamical cost, $J_{d}$, is illustrated in Fig. 1 and a detailed description is given in the caption. In general, the inversion of this model produces equally partitioned observational, $J_{o}$, and dynamical, $J_{d}$, costs. To further reduce the dynamical costs, observational costs are set to zero by assigning the newly estimated transport and tracer values to $\mathbf{x}_{o}$ and then repeating the minimization. Note that the integrated flux requirements in $\mathbf{x}_{o}$ are not adjusted and that the covariance matrices $\mathbf{P}$ and $\mathbf{Q}$ are held fixed. The process of updating $\mathbf{x}_{o}$ and inverting is repeated until the total cost, $J$, is negligible. Here, we choose the arbitrary cutoff of $J<10^{-5}$; the lower bound on $J$ appears to be limited only by machine precision. The resulting transport and density fields (see Fig. 2) almost perfectly satisfy the dynamical constraints.

In the second step, $\delta^{13} \mathrm{C}$ and ${ }^{14} \mathrm{C}$ fields are generated that are consistent with the transports found from the first set of inversions. At the northern boundary $\left(50^{\circ} \mathrm{N}\right)$ and at the upper level (1-km depth), $\delta^{13} \mathrm{C}$ is set to $1 \pm 1 \%$ and ${ }^{14} \mathrm{C}$ to a concentration of $1 \pm 1$ (i.e., $\Delta{ }^{14} \mathrm{C}=0 \pm$ $1000 \%$ ). At the southern boundary, east of the boundary current and in the deepest layer (i.e., $10^{\circ} \mathrm{N}, 15^{\circ}-35^{\circ}$ longitude, and $4-5-\mathrm{km}$ depth) $\delta^{13} \mathrm{C}$ is set to $0 \pm 1 \%$ and ${ }^{14} \mathrm{C}$ to $0.9 \pm 1$ (i.e., $\Delta^{14} \mathrm{C}=-100 \pm 1000 \%$ ). Although our model domain is too idealized to represent a particular ocean basin, we use these tracer values (not the 

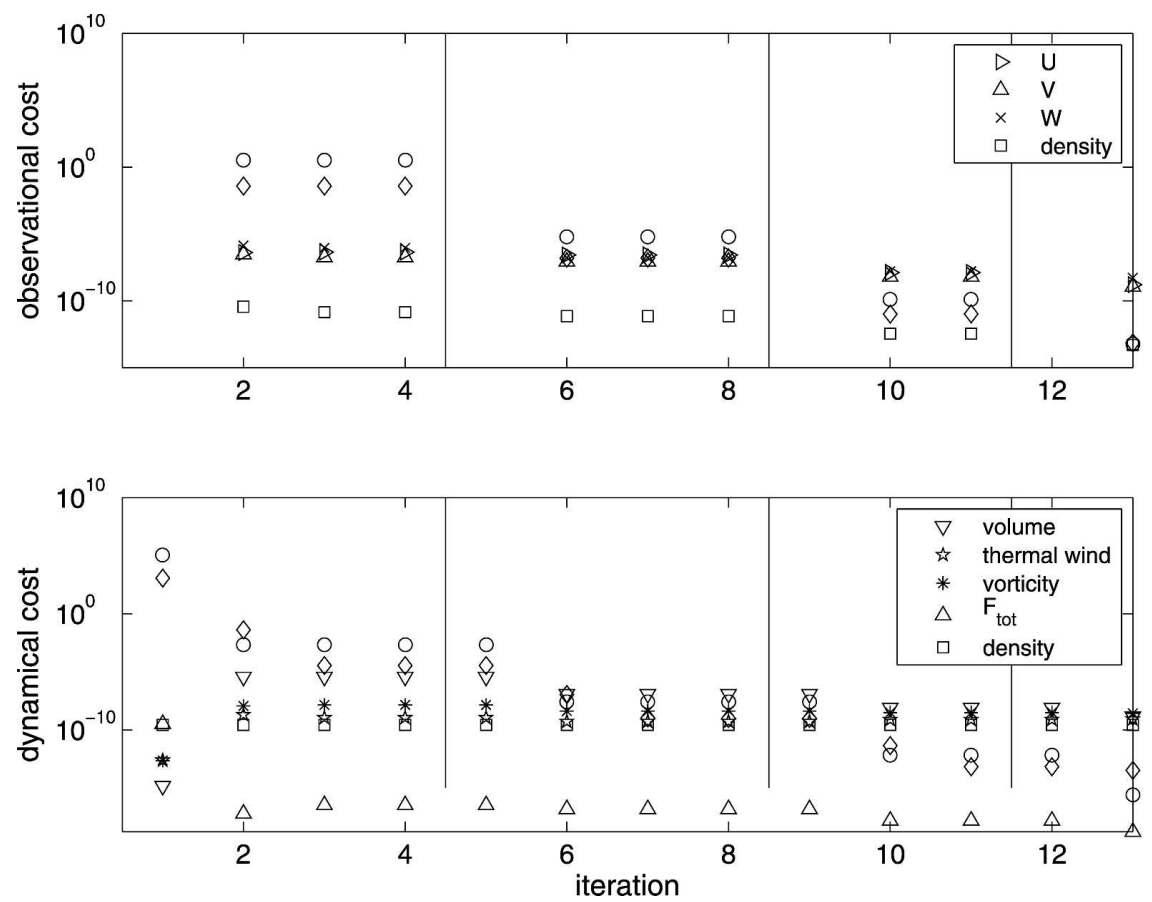

FIG. 1. Iterative minimization of the cost function for the reference model state. (top) The transport and density components of the observational cost, $J_{o}$. (bottom) The various contributions to the dynamical cost, $J_{d}$, comprising volume conservation, thermal wind balance, linear vorticity, integrated transport (labeled as $F_{\text {tot }}$ and including $F_{\text {deep }}$ ), and density conservation. Initially, the model state, $\mathbf{x}$, and prior state, $\mathbf{x}_{o}$, are set to zero and the total cost, $J=$ $J_{o}+J_{d}=10^{6}$, is due exclusively to the requirements for $15 \mathrm{~Sv}$ of southward transport and 5 Sv of northward transport. To minimize this cost, transports and density anomalies are generated that are associated with other observational and dynamical costs. By iteration 7 the nonlinear minimization procedure reduces costs so that $J_{o}$ and $J_{d}$ are each approximately one, but negligible further minimization of $J$ is made. To further reduce $J_{d}, \mathbf{x}_{o}$ is set equal to the state vector from iteration step 7 , as indicated by the vertical black line. Thus, $J_{o}$ is zero at iteration step 8. Subsequent iterations reduce $J_{d}$ at the expense of increasing $J_{o}$ until negligible further progress in minimizing $J$ is made. The process of setting $\mathbf{x}_{o}$ equal to $\mathbf{x}$ and minimizing continues until $J<10^{-5}$. Note that the $y$ axis is logarithmic.

uncertainty values), as they are in rough agreement with the $\delta^{13} \mathrm{C}$ and $\Delta^{14} \mathrm{C}$ estimates for the North Atlantic during the Last Glacial Maximum (Curry and Oppo 2005; Broecker et al. 2004). All other grid points are assigned $\delta^{13} \mathrm{C}$ values of $0.5 \pm 1 \%$ and ${ }^{14} \mathrm{C}$ concentrations of $0.95 \pm 1$ (i.e., $\Delta^{14} \mathrm{C}=-50 \pm 1000 \%$ ). Large tracer uncertainties are assigned so that the model can easily bring values into agreement with the transport field (much smaller tracer uncertainties will later be assigned). The transport and density fields, however, are fixed by assigning very small uncertainties of $\pm 0.001 \mathrm{~Sv}$ and $\pm 0.001 \mathrm{~kg} \mathrm{~m}^{-3}$, respectively. Minimization proceeds as described above until $J$ is again less than $10^{-5}$. The results of this second inversion will be referred to as the reference circulation (see Fig. 3). This reference circulation is a schematic permitting us to test the ability of various tracers to constrain the circulation.

\section{Using tracers to estimate transport}

A standard application of inverse techniques is to estimate transport fields compatible with a tracer distribution (e.g., Wunsch 1996). In this section we attempt to recover the reference transport field by inverting various sets of tracer fields. Transports are left virtually unconstrained at $0 \pm 100 \mathrm{~Sv}$, while tracers are assumed to be almost perfectly known with density uncertainties of $\pm 10^{-6} \mathrm{~kg} \mathrm{~m}^{-3}, \delta^{13} \mathrm{C}$ at $\pm\left(10^{-6}\right) \%$, and $\Delta^{14} \mathrm{C}$ at $\pm 10^{-6}$. Dynamical constraints are kept the same as for the reference inversion at $\pm 0.01 \mathrm{~Sv}$. The recovery of transports from the tracer field serves as a check of the consistency between the tracers and the transport.

First, density observations (sampled from the reference state) are alone inverted to estimate the associated transport field. The reconstructed transport field 

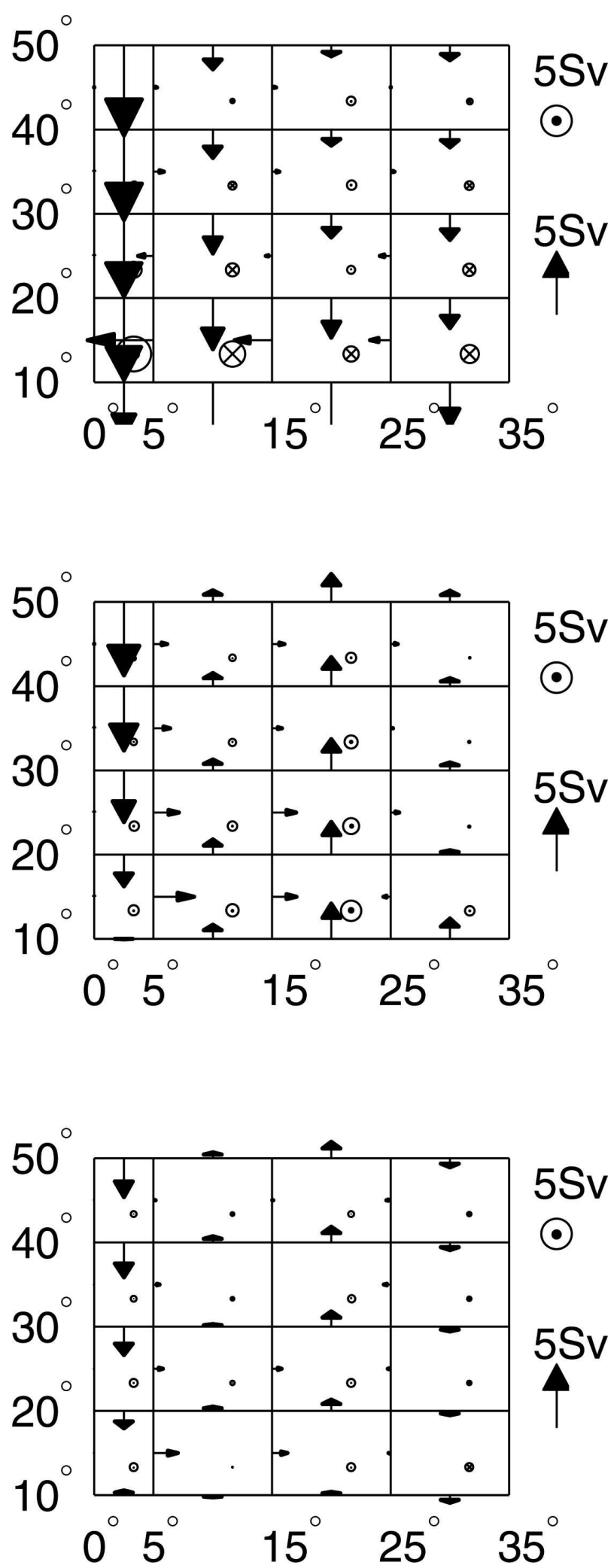
cate the longitude and latitude bounding each box and depth increases from the top $(1-2 \mathrm{~km})$ to the bottom grid $(3-4 \mathrm{~km})$. Arrows indicate horizontal transports and circles indicate vertical transports at the top of each box (dots indicate upward transport and x's downward). Scaling is given to the right where the vertical transport is proportional to the circle area. 
(a)

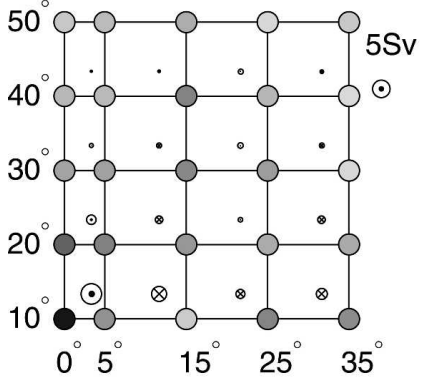

(b)

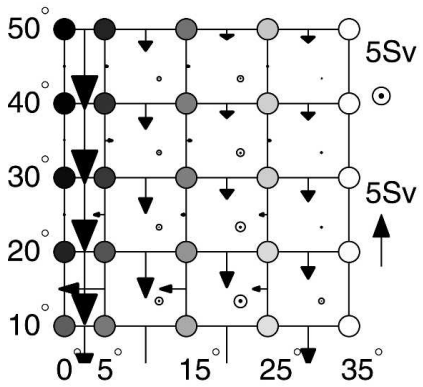

(c)

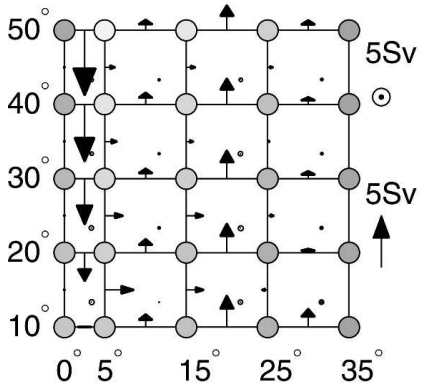

(d)

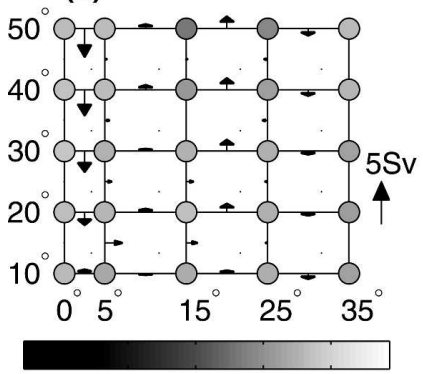

-0.06-0.04-0.02 00.02 (e)

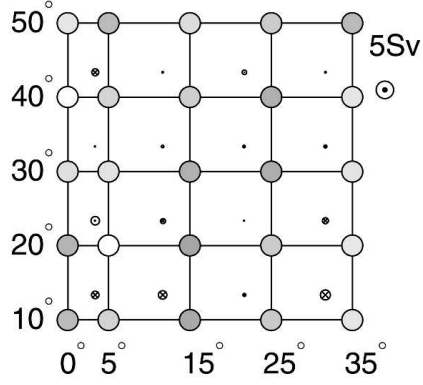

(f)

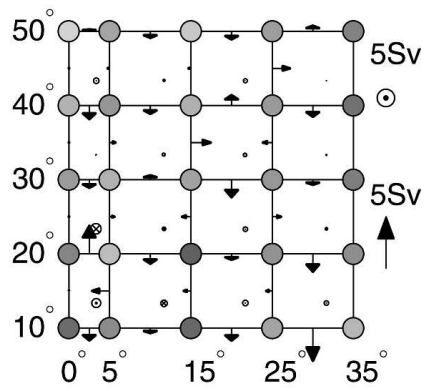

(g)

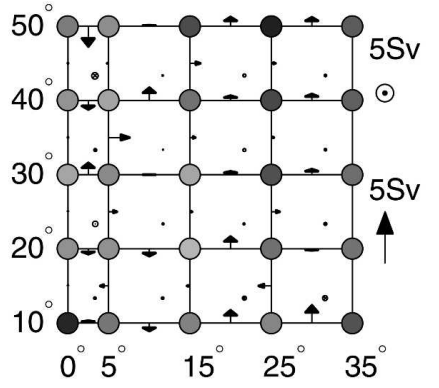

(h)

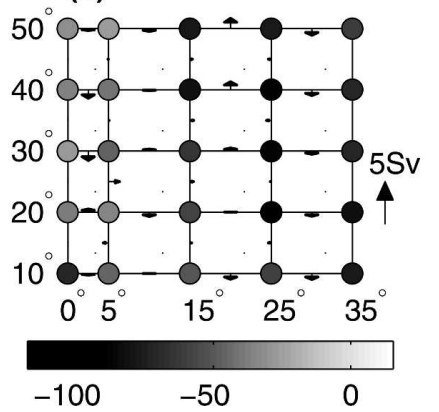

(i)

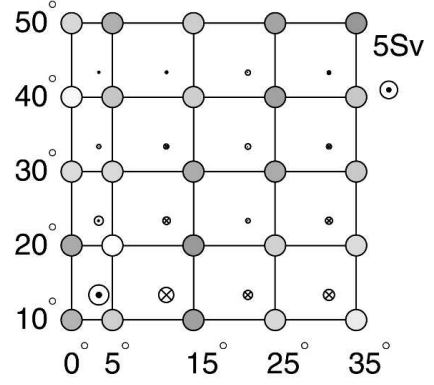

(j)

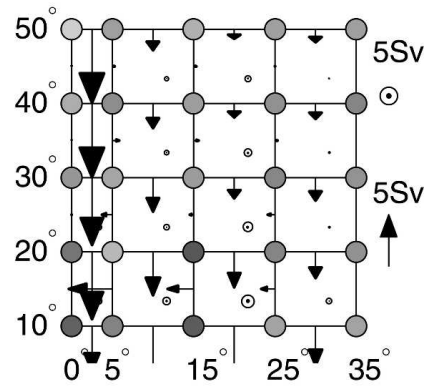

(k)

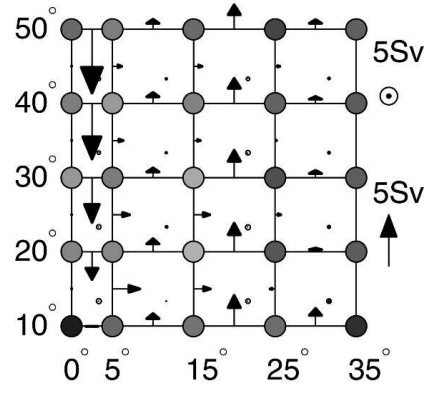

(I)

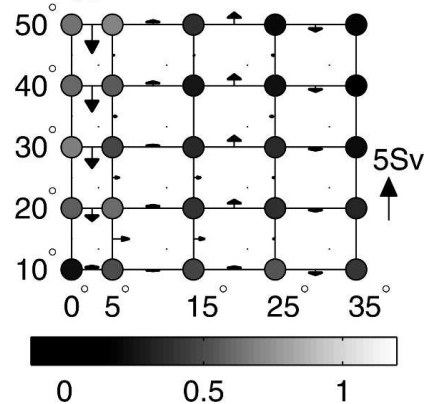

FIG. 3. Tracer fields for a hypothetical abyssal circulation. Rows correspond to vertical levels equally spaced from (top) 1 to (bottom) $4 \mathrm{~km}$. Each column depicts a different tracer: (a)-(d) density anomalies $\left(\mathrm{kg} \mathrm{m}^{-3}\right)$, (e)-(h) $\Delta^{14} \mathrm{C}(\%)$, and (i)-(l) $\delta^{13} \mathrm{C}(\%)$; values are indicated by the shading. Also shown are the reconstructed transports using various tracer fields: (a)-(d) density reconstruction, (e)-(h) $\Delta^{14} \mathrm{C}$ alone, and (i)-(l) $\Delta^{14} \mathrm{C}$ along with $\delta^{13} \mathrm{C}$. Tracer values are defined at the corners of each box, while velocities are defined at the center of each face. Thus, velocity is represented at three levels (as in Fig. 2) while tracers are represented at four levels. 
The primary signal indicated by the radiocarbon "observations" appears to be due to the mixture of northern and southern source waters; the effects of radiocarbon decay are secondary [this is analogous to the situation in the North Atlantic; see Broecker (1979) and Bolin et al. (1987)]. The total meridional transport in our reference circulation is $15 \mathrm{~Sv}$, giving a flushing time scale of roughly $50 \mathrm{yr}$. Because radiocarbon's half-life is two orders of magnitude larger, the change in $\Delta^{14} \mathrm{C}$ owing to radioactive decay is only about $5 \%$. Thus, the majority of the change in $\Delta^{14} \mathrm{C}$, roughly $100 \%$, owes to differences in the ratio of the northern and southern source waters. Only the relatively small nonconservative portion of the $\Delta^{14} \mathrm{C}$ signal provides a constraint on the rates of transport. Were the half-life of radiocarbon shorter or the meridional transport smaller, radiocarbon would provide a stronger constraint for determining the rates of the circulation.

\section{Bounding the transport}

So far only the circulation most consistent with the tracers has been considered. Given that the initial tracer distributions are fully consistent with the model itself, the ability to partially reproduce the associated transport pattern is a weak demonstration of the ability to estimate the circulation. Now we turn to a more demanding task of the tracers, that of placing an upper and lower limit on the total meridional transport, $F_{\text {tot }}$. In particular, we wish to estimate the observations required to constrain $F_{\text {tot }}$ to within a factor of 2 .

\section{a. Technique}

For the case of a purely linear system, a singular value decomposition of the $\mathbf{A}$ matrix would indicate what elements of the solution could be constrained [i.e., are in the range of A; see Wunsch (1996)]. In our case, however, the nonlinear advective terms in the model equations require an iterative approach toward minimizing the cost. At each step of the minimization the model equations are linearized around $\mathbf{x}$ and the $\mathbf{A}$ matrix is recomputed. Thus, the singular value decomposition of $\mathbf{A}$ only informs us about perturbations around the linearized state, and a more general approach is required if we are to determine the extent to which a tracer field constrains the transport.

We seek to place upper and lower bounds on the meridional mass transport by determining when a circulation is not consistent with a tracer distribution. Thus, we adopt a null hypothesis, $\mathrm{H}_{2 \times}$, that the total meridional transport, $F_{\text {tot }}$, was double that of the reference circulation and we determine what observations are required to reject it. To be confident that the rejection of $\mathrm{H}_{2 \times}$ is warranted, it is necessary to find the model state that meets (i) the integrated transport constraints and (ii) the dynamical constraints but (iii) requires as little change to the tracer field as possible. Each element of this condition is described in turn. The lower bound on transport rates will be dealt with later.

(i) The integrated transport is specified to be $F_{\text {tot }}=$ $30 \pm 1 \mathrm{~Sv}$, double that of the reference state. The small uncertainty of $\pm 1 \mathrm{~Sv}$ ensures that the model will almost exactly meet the integrated transport requirements. The individual transports specified in $\mathbf{x}_{o}$ are doubled from those of the reference state so that, initially, there are no inconsistencies between the individual transports and the integrated transport requirements. Unlike the integrated transports, individual transports are permitted to freely vary by assigning the same uncertainties as in the reference inversion $(0 \pm 20,0 \pm 15$, and $0 \pm$ $10 \mathrm{~Sv}$ in the upper, middle, and deepest layers, respectively).

(ii) The dynamical constraints are considered to be satisfactorily met when the dynamical cost, $J_{d}$ [see Eq. (9)], is less than one. Dynamical constraints are assigned uncertainties of $\pm 0.01 \mathrm{~Sv}$. The combination of assigning such small dynamical uncertainties and requiring $J_{d}<1$ means that dynamical constraints must be almost perfectly met. As noted earlier, requiring such small dynamical imbalances is unrealistic, but provides the best chance for tracers to constrain the circulation.

(iii) It is necessary to search for the model state that requires as little change to the tracer field as possible. The uncertainty assigned to the tracer field is left as a variable, $\mu$. The discussion below is for a generic tracer field, specifics are discussed in section $4 \mathrm{~b}$. The search strategy generally entails increasing $\mu$ until inversion of the tracer field yields a transport field having $J_{d}<1$. There are, however, two complications. First, although increasing $\mu$ typically leads to larger changes in the tracer field and a smaller $J_{d}$, this is not always the case, presumably owing to the model nonlinearities. Second, minimization of the cost function can result in a local rather than global minimum. To address these complications, a simulated annealing algorithm (e.g., Press et al. 1999) is used to search for the state requiring the smallest adjustment to the tracer field.

The search begins by assigning an initial tracer uncertainty, $\mu_{o}$, and inverting for the transport field. For simplicity, the tracer uncertainties are assumed uniform over the entire model domain. If the inversion results in $J_{d} \geq 1, \mu$ is increased by a random amount, permitting 
the model to more freely vary the tracer field. If $J_{d}<1$, $\mu$ is decreased by a random amount. The expected magnitude of the change in $\mu$ is slowly decreased, so that the search gradually focuses around values tending to give a value of $J_{d}$ that is near 1 . Whenever $J_{d}<1$, the mean square difference (not the cost) between the reference tracer field, $t_{o}$, and the new tracer field, $t_{n}$, is computed as $L_{t}=1 / N \times \sum_{i=1}^{N}\left(t_{o i}-t_{n i}\right)^{2}$. If $L_{t}$ is smaller than that associated with any previous model state, the model state is saved as $\mathbf{x}_{\text {best }}$ for use as the (approximate) starting point in subsequent inversions. To help to prevent getting trapped in a local minimum, the minimization is initiated from a perturbation of $\mathbf{x}_{\text {best }}$ where each transport term is perturbed by $\pm 1 \mathrm{~Sv}$. Although it is not possible to ensure the solution is a global minimum, multiple runs of the minimization procedure yield consistent results, suggesting the technique is stable. Note that further minimization of $L_{t}$ would make it more difficult to reject $\mathrm{H}_{2 \times}$, a task that in section $4 \mathrm{~b}$ is shown to already be difficult.

Having a method to estimate the smallest value for $L_{t}$, it still remains to determine what level of data accuracy is required to distinguish $L_{t}$ from the observational noise. A $\chi^{2}$ test (e.g., Devore 2000) is used to determine when $L_{t}$ is significantly larger than expected for observational noise having variance $\sigma^{2}$. The observational noise, $\sigma$, is distinct from the parameter controlling how much the model can adjust the tracer values, $\mu$. The variable $\sigma$ is made as large as possible while still permitting rejection of the null hypothesis at the 0.05 significance level. That is, for data with an uncertainty of $\pm \sigma$, there would be a $5 \%$ chance of incorrectly accepting $\mathrm{H}_{2 \times}$ as true. (The $\sigma$ value is similar in concept to determining the $p$ value for a statistical test.) For the results reported here, the variance represented by $L_{t}$ is always more significant than the mean differences between the reference and new tracer field, as judged using a Student's $t$ test. Note that the $\chi^{2}$ test does not take into account patterns in the residuals that might also be useful for rejecting the null hypothesis.

\section{b. Upper bound}

Using the technique described above, the $\mathrm{H}_{2 \times}$ null hypothesis of a doubling of the total meridional transport is evaluated using the density and $\Delta^{14} \mathrm{C}$ "observations" individually and then coupled with $\delta^{13} \mathrm{C}$. For density alone, $\mathrm{H}_{2 \times}$ can be met with a slight tracer adjustment, about $\pm 0.001 \mathrm{~kg} \mathrm{~m}^{-3}$. Increasing the barotropic transport in the western boundary current is found to require the least change in density (see Figs. $4 a-d)$. This is because the thermal wind does not constrain barotropic changes in the transport and the vorticity balance is not imposed in the western boundary current; weak constraint only comes from density conservation.

Three modifications to the model are considered for improving the ability of the density observations to constrain the circulation. In the first, assuming the lowest level is at rest resolves the indeterminacy of the thermal wind, but is a rather questionable assumption. Proxies of the bottom velocity (e.g., McCave et al. 1995) may help to rule out barotropic shifts in the transport once they are quantitatively interpreted in terms of velocity and become widely available. In the context of estimating modern meridional transports, it has been found that an accurate estimate of the bottom velocity is critical (Baehr et al. 2004).

A second option for improving the density constraints on the circulation is to extend the model domain to the surface. This provides the additional constraint that the transports in the upper and lower branches of the meridional circulation must approximately balance. However, the representation of the upper ocean admits further uncertainties because the wind stress and the associated Ekman transport are virtually unknown for the geologic past. For the modern ocean the Ekman transport across $11^{\circ} \mathrm{N}$ in the Atlantic is as much as $10 \mathrm{~Sv}$ (Chereskin and Roemmich 1991), thus constituting an important component of the meridional circulation. Ganachaud (2003) illustrates that while enforcing mass conservation in the deepest layers is acceptable, variations in the Ekman transport will cause geostrophic estimates in the surface layer to be inaccurate, and recommends against imposing strict top to bottom mass conservation in geostrophic inversions. Further work is warranted using a model that explicitly includes wind-driven circulation effects, but is beyond the scope of the present study.

The third option for improving the constraints on the circulation is to incorporate additional proxies able to constrain independent features of the circulation. Here, we use $\delta^{13} \mathrm{C}$ in conjunction with the density observations. It is assumed that $\delta^{13} \mathrm{C}$ is known at every grid point to within $\pm 0.01 \%$. Note that the actual uncertainty is closer to $\pm 0.1 \%$ o (e.g., Curry and Oppo 2005) but that $\delta^{13} \mathrm{C}$ would then give negligible additional constraint on the circulations. An increase in the barotropic western boundary transport now would require an increase in $\delta^{13} \mathrm{C}$ values in the deep southwestern region of the model and is no longer acceptable. Instead, the transport is primarily increased in the upper two layers and this manifests itself as a geostrophic adjustment to the density field (see Figs. 4e-h). That larger density adjustments are required when $\delta^{13} \mathrm{C}$ is incorporated is important, particularly because $\delta^{13} \mathrm{C}$ does not of itself constrain the net meridional circulation. 
(a)

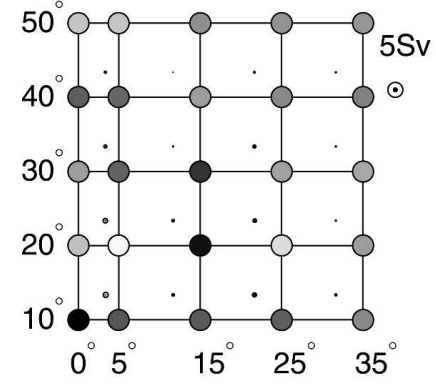

(b)

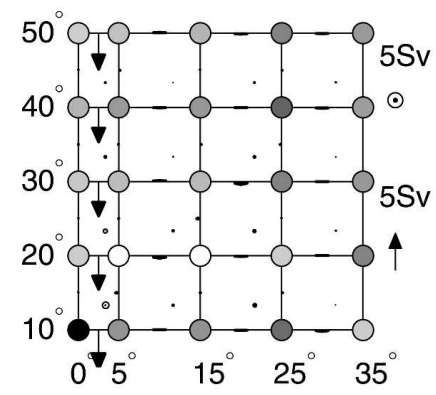

(c)

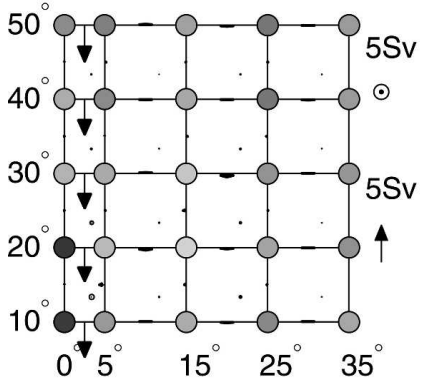

(d)

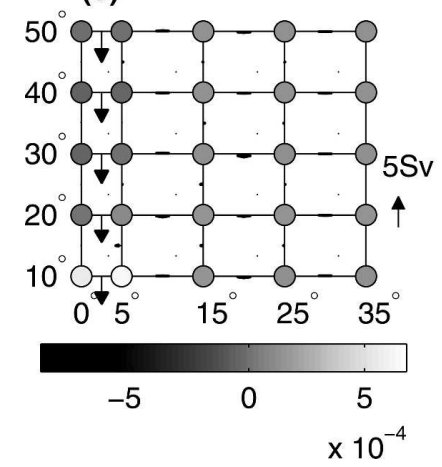

(e)

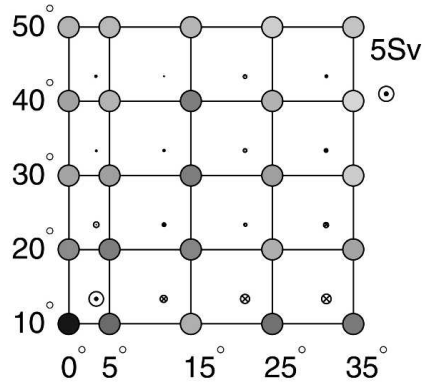

(f)

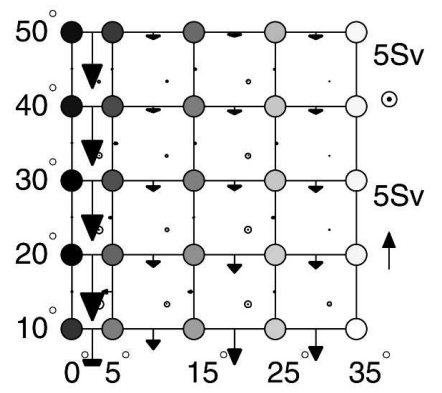

(g)

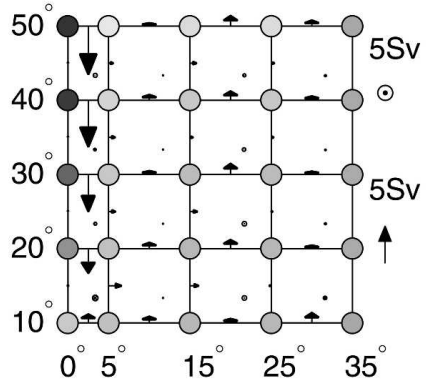

(h)

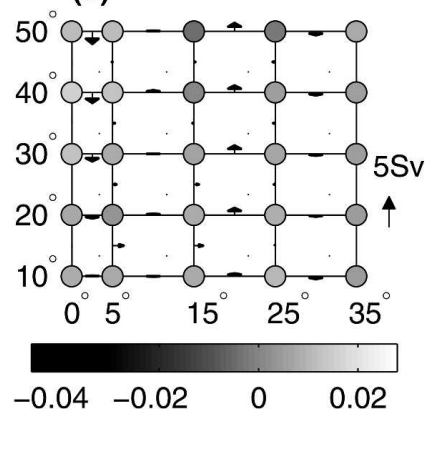

(i)

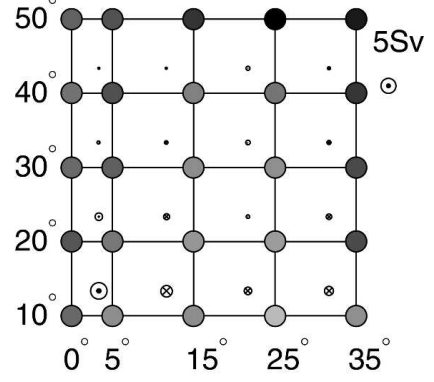

(j)

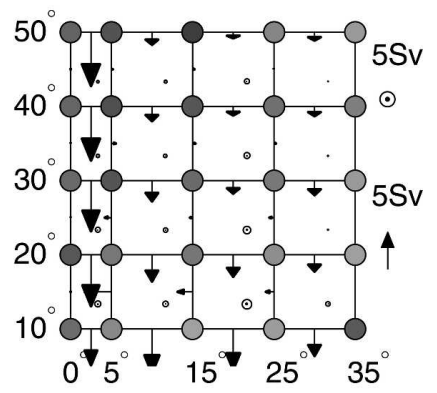

(k)

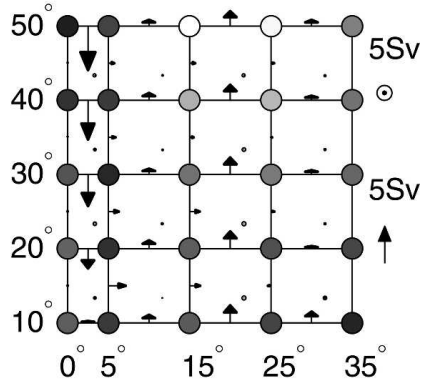

(I)

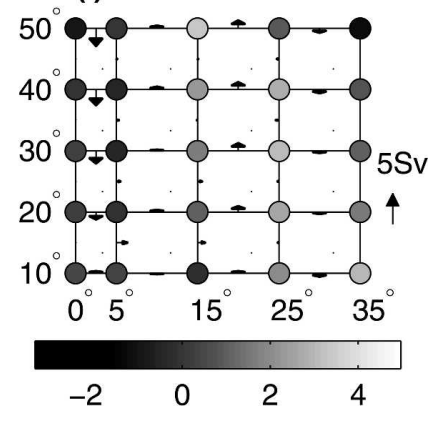

FIG. 4. Double meridional mass transport null hypothesis, $\mathrm{H}_{2 \mathrm{x}}$. Shown is the change in circulation that meets both the 30-Sv southward transport and dynamical requirements while producing the smallest change in the tracer field. Change in transport and tracers are shown for (a)-(d) density, (e)-(h) density when paired with $\delta^{13} \mathrm{C}$, and (i)-(l) $\Delta^{14} \mathrm{C}$ when paired with $\delta^{13} \mathrm{C}$. 
(a)

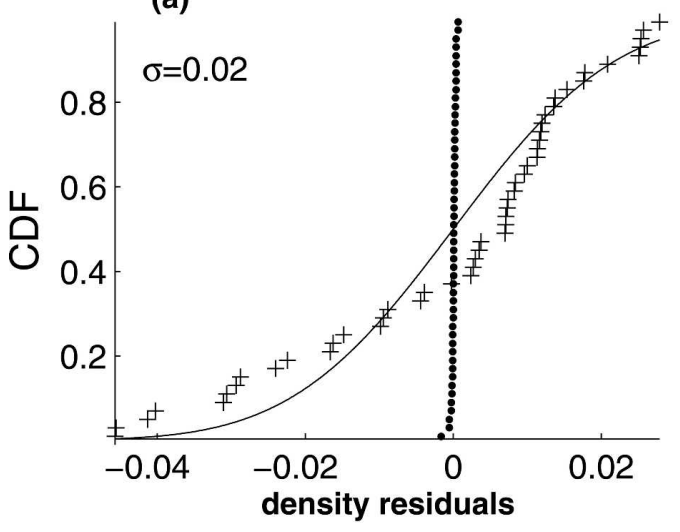

(c)

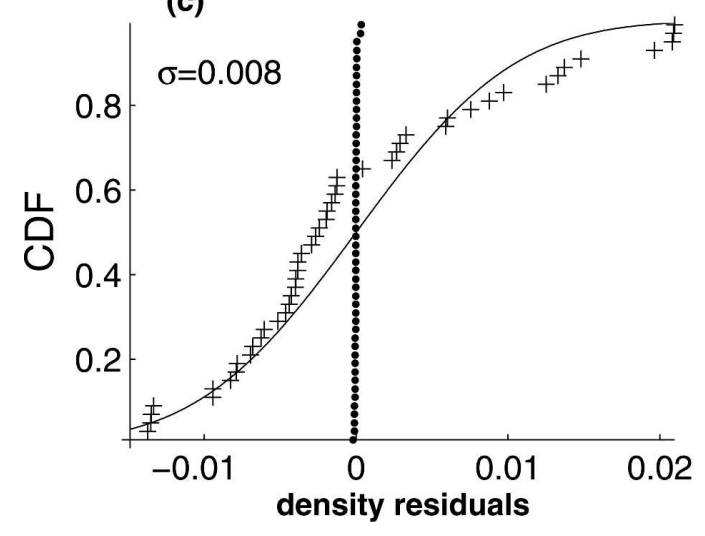

(b)

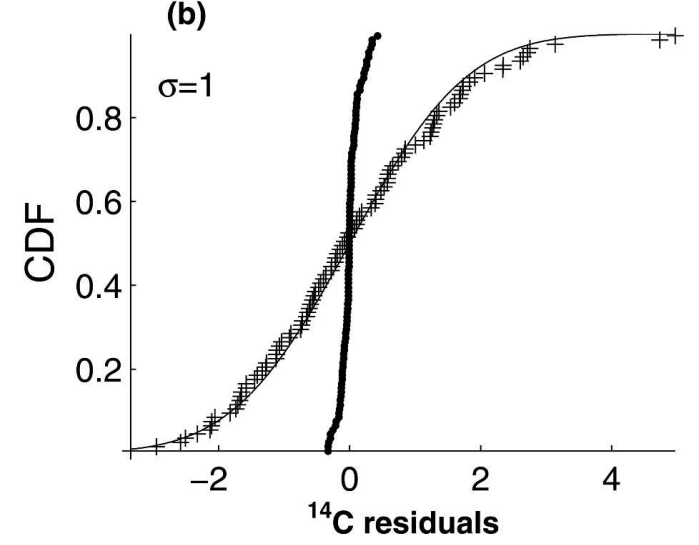

(d)

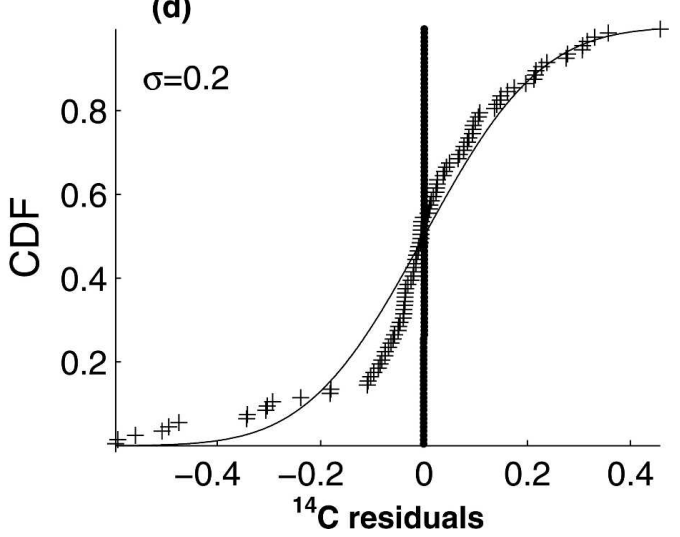

FIG. 5. Cumulative distribution function (CDF) for the $\mathrm{H}_{2 \mathrm{X}}$ and $\mathrm{H}_{\mathrm{X} / 2}$ null hypotheses (see text). (a) The CDF of the change in density required for a doubling of the net meridional transport, $\mathrm{H}_{2 \mathrm{X}}$. Two cases are shown, using density alone (dots) and when the circulation is simultaneously constrained using density and $\delta^{13} \mathrm{C}$ (crosses). The solid line shows the CDF of a normal distribution with 0.02 standard deviation. This is the maximum permissible uncertainty in the density measurement while still allowing the null hypothesis to be rejected at the 0.05 significance level when the $\delta^{13} \mathrm{C}$ constraint is also used. (b) Results for $\Delta^{14} \mathrm{C}$ alone (dots) and $\Delta^{14} \mathrm{C}$ along with $\delta^{13} \mathrm{C}$. (c), (d) The same as in (a), (b) but for the half-transport null hypothesis, $\mathrm{H}_{\mathrm{X} / 2}$.

The cumulative distribution function of the changes in density is shown in Fig. 5a. If the $\delta^{13} \mathrm{C}$ and density values were thought to be accurate to within $\pm 0.01 \%$ and $\pm 0.02 \mathrm{~kg} \mathrm{~m}^{-3}$ respectively, there would only be a small probability $(\leq 0.05)$ that the observations are compatible with a doubled meridional transport. The actual paleodensity accuracy is, however, closer to \pm 0.2 $\mathrm{kg} \mathrm{m}^{-3}$ (see Lynch-Stieglitz 2001), an order of magnitude more uncertain. The paleodensity is highly uncertain because of difficulties in estimating both paleosalinities, currently available at only a few isolated locations (e.g., Adkins et al. 2002), and paleotemperatures of bottom water. Note that the use of paleodensity may be more beneficial in the upper ocean where crossbasin density changes are larger (see Lynch-Stieglitz 2001) but where surface buoyancy and wind stress forcings enter as important unknowns.
Next, the $\Delta^{14} \mathrm{C}$ observations are considered. When $\Delta^{14} \mathrm{C}$ alone is used to constrain the model, an observational accuracy of $\pm 0.1 \%$ is required to reject $\mathrm{H}_{2 \times}$. The more rapid southerly transport required by $\mathrm{H}_{2 \times}$ leaves less time for radioactive decay, tending to decrease the north-south gradients in $\Delta^{14} \mathrm{C}$. But such an increase in $\Delta^{14} \mathrm{C}$ activity is partially compensated for by increasing the transport of low $\Delta^{14} \mathrm{C}$ from the south. Similar to the finding in section 3, the inclusion of the $\delta^{13} \mathrm{C}$ observations substantially increases the constraints on the circulation, and the permissible uncertainty increases to $\pm 1 \%$ (see Figs. $4 \mathrm{i}-\mathrm{l}$ and $5 \mathrm{~b}$ ). Still, the actual uncertainty in the paleoceanographic estimates of $\Delta^{14} \mathrm{C}$ appears to be roughly $\pm 50 \%$ (Keigwin 2004; Broecker et al. 2004). Extending the model domain to cover the entire globe may improve the ability of radiocarbon to constrain the circulation, particularly if global $\Delta^{14} \mathrm{C}$ coverage be- 
comes available, although with the present uncertainties true constraint appears infeasible.

\section{c. Lower bound}

The main point has perhaps already been madebounding the net meridional circulation is difficult given present uncertainties in the paleotracers-but for completeness we briefly discuss establishing a lower bound on the circulation. The null hypothesis that integrated meridional flux is reduced by one-half, $\mathrm{H}_{\times / 2}$, is evaluated using the same procedure as for $\mathrm{H}_{2 \times}$, but now requiring that $F_{\text {tot }}=-7.5 \pm 1 \mathrm{~Sv}$ and reducing the individual transports by one-half.

It is somewhat more difficult to rule out this null hypothesis of reduced flow. For density this is because the change in the meridional transport $(-7.5 \mathrm{~Sv})$ has only one-half of the magnitude associated with $\mathrm{H}_{2 \times}$ $(+15 \mathrm{~Sv})$. The reduced transport does provide more time for radioactive decay, but low radiocarbon values present in the reference model state are primarily due to southern source waters being depleted. The reduction of southern source waters compensates for the increased residence time demanded by the $\mathrm{H}_{\times / 2}$ scenario. As pointed out by Wunsch (2003), the presence of an open southern boundary permits $\Delta^{14} \mathrm{C}$ concentrations within the model basin to vary almost independently of changes in the transport.

Residuals for the density and $\Delta^{14} \mathrm{C}$ are shown in Figs. $5 \mathrm{c}$ and $5 \mathrm{~d}$ both with and without the additional $\delta^{13} \mathrm{C}$ constraint. In each case, greater observational accuracy is required to rule out $\mathrm{H}_{\times / 2}$ rather than for $\mathrm{H}_{2 \times}$. Note that the more extreme null hypothesis that past circulation was at rest is much more easily ruled out. The presence of any significant radioactivity or horizontal density gradient would permit the rejection of such a no-transport null hypothesis.

\section{d. Reduced observations}

Last, we consider a somewhat more realistic scenario where observations are only available at the nominal sediment-water interface: the eastern and western margins and the bottom of the model domain. Thus, the interior of the domain is left unconstrained by observations. Now, even when $\delta^{13} \mathrm{C}$ is paired with either density or $\Delta^{14} \mathrm{C}$, it is not possible to bound the circulation. In analogy with a linear system, $F_{\text {tot }}$ appears to lie within the null space of the model. Apparently, any tracer value can be generated by the transport of unconstrained interior values to the margins. This permits the $\delta^{13} \mathrm{C}$ and $\Delta^{14} \mathrm{C}$ observations to be unaltered in the presence of a stronger transport, and in the case of the density tracer, for the barotropic flux in the boundary current to be adjusted without bound.
The ability to constrain the meridional transport is curtailed when interior points of the model domain are left unspecified. Making observations at seamounts, islands, and ridges may thus provide valuable constraints on the circulation. Specification of nonzero covariance between observations may also increase the control on the circulation. Some constraint on the circulation is possible if the dubious assumption is made that the lower-level transports are zero; in this case, the density sampled only at the eastern and western margins is able to constrain the net meridional mass transport to a level comparable to that previously found for the density and $\delta^{13} \mathrm{C}$ sampled on the entire model grid (not shown). Extending the model to the surface and assuming the Ekman flux to be well constrained also enables the density measurements at the margins to constrain the meridional circulation, in keeping with the results obtained from other models (Hirschi and Marotzke 2007).

\section{Further discussion and conclusions}

In this paper we have considered the extent to which tracer observations can place upper and lower bounds on the integrated meridional transport. The methodology adopted is to search for the transport pattern that meets the dynamical and integrated flux requirements while requiring the smallest tracer adjustment. Although this makes it difficult to rule out even large changes in meridional transport, such an approach is necessary if one is to distinguish plausible inferences regarding the circulation from what the tracers truly require.

In this highly idealized ocean basin, bounding the meridional circulation within a factor of 2 requires the observations to have uncertainties an order of magnitude smaller than are currently attainable. Extending the model domain to include the surface layers may aid in further constraining the circulation, but only if both the Ekman and geostrophic components of the transport can be adequately constrained. We anticipate that constraining the actual ocean circulation will be no simpler than this exercise. If anything, we have been overly optimistic in assuming that observations are available over the entire model grid and are fully consistent with the model. Furthermore, we have assumed that the dynamics are met to within a hundred times greater accuracy than is likely to be the case and that the circulations are in steady state. It thus appears that the bounding rates of the integrated meridional transport is not now possible using $\delta^{13} \mathrm{C}$, paleodensity, or radiocarbon estimates.

One option is to change the questions we seek to answer about the past oceans. Constraining volumes of past water using paleotracers seems to be a much more 
straightforward exercise, one that does not require a rate-setting clock. The more climatically relevant questions, however, have to do with the transport of heat and other quantities. Although a detailed understanding of the spatial distribution of these quantities is also required, accurate determination of the past mass transport would bring us closer to understanding the role of the oceans in maintaining and causing past climate states.

A question that arises is why past meridional circulation is so uncertain when the modern circulation can be accurately determined (e.g., Ganachaud and Wunsch 2000; Hirschi et al. 2003). There are several reasons, the most important being the difference in the accuracy of the measurements. For example, paleodensity estimates are 100 times more uncertain than their modern counterparts. Proxies for wind speed and current velocity are even more uncertain. Another reason is that paleoproxies tend to only monitor properties at the sediment-water interface, thus curtailing the ability to constrain the conditions in the interior ocean. Finally, it should be noted that modern oceanography has only been able to accurately estimate the meridional circulation within the last few decades. By comparison, paleoceanography is a young science working with a relatively limited observational set. We do not contend that constraining the past meridional circulation is impossible, but rather that improvements in our observational and modeling strategies will be required.

This study offers some clues in how to proceed toward constraining the past meridional circulation rates. While $\delta^{13} \mathrm{C}$ (when considered as a conservative tracer) is individually unable to constrain the transport rates, it does improve the constraints on transport rates when paired with either density or $\Delta^{14} \mathrm{C}$ observations. Thus, as one might anticipate, the best constraints on ocean circulation will likely come from combining as many proxies as possible. Another clue is that integrative measures, such as those provided by density at the ocean margins, are less affected by the inability to measure tracers at interior points. Other proxies may also prove useful individually or in combination with the proxies discussed here. Legrand and Wunsch (1995) concluded that a clock is required to constrain rates of flow. We might add that the clock needs to be accurate, keep time in the interior, and work well in concert with conservative tracers.

Acknowledgments. Recently one of us was at Carl's home. A neighbor was inadvertently locked out of her house and Carl went over to help. Being unable to pry any of the windows or get a locksmith on a holiday weekend, Carl found a brick in the yard and used it to strike a window pane in the door. The pane would not give until a sufficiently hard blow broke the window but also cut Carl's hand. Returning home, when asked what happened, Carl merely suggested that in the future one should use a bigger brick. The generosity and determination bespoken in this small incident are also apparent in Carl's dealings with colleagues and science: a generosity with time, ideas, and insight; and a determination in finding a solution. We thank Carl for his ongoing mentorship, inspiration, and (in the sense of stirring to action) his provocation.

The first author is supported by the NOAA Postdoctoral Program in Climate and Global Change and GG by the National Ocean Partnership Program (ECCO). Author OM acknowledges support from the National Science Foundation; W. Curry and J. Hirschi provided very useful comments.

\section{REFERENCES}

Adkins, J. F., and E. A. Boyle, 1997: Changing atmospheric $\Delta^{14} \mathrm{C}$ and the record of deep water paleoventilation ages. Paleoceanography, 12, 337-344.

— , K. McIntyre, and D. Schrag, 2002: The salinity, temperature, and $\delta^{18} \mathrm{O}$ of the glacial deep ocean. Science, 298, 1724-1725.

Baehr, J., J. Hirschi, J. Beismann, and J. Marotzke, 2004: Monitoring the meridional overturning circulation in the North Atlantic: A model-based array design study. J. Mar. Res., 62, 283-312.

Bolin, B., A. Björkström, K. Holmén, and B. Moore, 1987: On Inverse Methods for Combining Chemicals and Physical Oceanography Data: A Steady-State Analysis of the Atlantic Ocean. International Meteorological Institute in Stockholm, $134 \mathrm{pp}$.

Boyle, E., 1988: Vertical oceanic nutrient fractionation and glacial/interglacial $\mathrm{CO}_{2}$ cycles. Nature, 331, 55-56.

— 1992: Cadmium and $\delta^{13} \mathrm{C}$ paleochemical ocean distributions during the stage 2 glacial maximum. Annu. Rev. Earth Planet. Sci., 20, 245-287.

_ , and L. Keigwin, 1987: Deep circulation of the North Atlantic over the last 20,000 years: Geochemical evidence. Science, 218, 784-787.

Broecker, W. S., 1979: A revised estimate for the radiocarbon age of North Atlantic deep water. J. Geophys. Res., 84, 32183226.

_ , and T. H. Peng, 1982: Tracers in the Sea. Lamont-Doherty Earth Observatory, $690 \mathrm{pp}$.

__ E. Clark, I. Hajdas, and G. Bonani, 2004: Glacial ventilation rates for the deep Pacific Ocean. Paleoceanography, 19, PA2002, doi:10.1029/2003PA000974.

Chereskin, T., and D. Roemmich, 1991: A comparison of measured and wind-derived Ekman transport at $11^{\circ} \mathrm{N}$ in the Atlantic Ocean. J. Phys. Oceanogr., 21, 869-878.

Clark, P. U., N. G. Pisias, T. F. Stocker, and A. J. Weaver, 2002: The role of the thermohaline circulation in abrupt climate change. Nature, 415, 863-869.

Curry, W. B., and D. W. Oppo, 2005: Glacial water mass geometry and the distribution of $\delta^{13} \mathrm{C}$ of $\sigma \mathrm{CO}_{2}$ in the western Atlantic Ocean. Paleoceanography, 20, PA1017, doi:10.1029/ 2004PA001021. 
—, J.-C. Duplessy, L. D. Labeyrie, and N. J. Shackleton, 1988: Changes in the distribution of $\delta^{13} \mathrm{C}$ of deepwater $\Sigma \mathrm{CO}_{2}$ between the last glaciation and the Holocene. Paleoceanography, 3, 317-341.

Devore, J., 2000: Probability and Statistics for Engineering and the Sciences. Duxbury, 775 pp.

Duplessy, J.-C., N. J. Shackleton, R. K. Matthews, W. Prell, W. F. Ruddiman, M. Caralp, and C. H. Hendy, 1984: ${ }^{13} \mathrm{C}$ record of benthic foraminifera in the last interglacial ocean: Implications for the carbon cycle and the global deep water circulation. Quat. Res., 21, 225-243.

, R. G. Fairbanks, L. Labeyrie, D. Oppo, and N. Kallel, 1988: Deepwater source variations during the last climate cycle and their impact on the global deepwater circulation. Paleoceanography, 3, 343-360.

Ganachaud, A., 2003: Error budget of inverse box models: The North Atlantic. J. Atmos. Oceanic Technol., 20, 1641-1655.

— circulation, heat transport and mixing from hydrographic data. Nature, 408, 453-457.

Gebbie, G., and P. Huybers, 2006: Meridional circulation during the Last Glacial Maximum explored through a combination of South Atlantic $\delta^{18} \mathrm{O}$ observations and a geostrophic inverse model. Geochem. Geophys. Geosyst., 7, Q11N07, doi:10.1029/2006GC001383.

Hirschi, J., and J. Marotzke, 2007: Reconstructing the meridional overturning circulation from boundary densities and the zonal wind stress. J. Phys. Oceanogr., in press.

—, J. Baehr, J. Marotzke, J. Stark, S. Cunningham, and J. Beismann, 2003: A monitoring design for the Atlantic meridional overturning circulation. Geophys. Res. Lett., 30, 1413, doi:10.1029/2002GL016776.

Keigwin, L. D., 2004: Radiocarbon and stable isotope constraints on Last Glacial Maximum and Younger Dryas ventilation in the western North Atlantic. Paleoceanography, 19, PA4012, doi:10.1029/2004PA001029.

Kroopnick, P. M., 1985: The distribution of ${ }^{13} \mathrm{C}$ of $\mathrm{TCO}_{2}$ in the world oceans. Deep-Sea Res., 32, 57-84.

Legrand, P., 1995: What do paleo-geochemical tracers tell us about the deep ocean circulation during the last ice age? Ph.D. thesis, Massachusetts Institute of Technology, 194 pp.

— , and C. Wunsch, 1995: Constraints from paleotracer data on the North-Atlantic circulation during the last glacial maximum. Paleoceanography, 10, 1011-1045.

Lynch-Stieglitz, J., 2001: Using ocean margin density to constrain ocean circulation and surface wind strength in the past. Geochem. Geophys. Geosyst., 2, doi:10.1029/2001GC000208.

_ W. Curry, and N. Slowey, 1999: A geostrophic transport estimate for the Florida Current from the oxygen isotope composition of benthic foraminifera. Paleoceanography, 14, 360-373.

- - D. W. Oppo, U. S. Ninneman, C. D. Charles, and J. Munson, 2006: Meridional overturning circulation in the South Atlantic at the Last Glacial Maximum. Geochem. Geophys. Geosyst., 7, Q10N03, doi:10.1029/2005GC001226.

Marchal, O., R. Francois, T. Stocker, and F. Joos, 2000: Ocean thermohaline circulation and sedimentary $\mathrm{Pa}-231 / \mathrm{Th}-230 \mathrm{ra}-$ tio. Paleoceanography, 15, 625-641.

Marchitto, T. M., W. B. Curry, and D. W. Oppo, 1998: Millennialscale changes in North Atlantic circulation since the last glaciation. Nature, 393, 557-561.

— D. W. Oppo, and W. Curry, 2002: Paired benthic foraminiferal $\mathrm{Cd} / \mathrm{Ca}$ and $\mathrm{Zn} / \mathrm{Ca}$ evidence for a greatly increased pres- ence of Southern Ocean water in the glacial North Atlantic. Paleoceanography, 17, 1038, doi:10.1029/2000PA000598.

Matsumoto, K., J. Lynch-Stieglitz, and R. F. Anderson, 2001: Similar glacial and Holocene Southern Ocean hydrography. Paleoceanography, 16, 445-454.

McCave, I., B. Manighetti, and N. A. S. Beveridge, 1995: Circulation in the glacial North Atlantic inferred from grain-size measurements. Nature, 374, 149-152.

McManus, J. F., R. Francois, J.-M. Gherardi, L. D. Keigwin, and S. Brown-Leger, 2004: Collapse and rapid resumption of Atlantic meridional circulation linked to deglacial climate changes. Nature, 428, 834-837.

Mercier, H., 1989: A study of the time averaged circulation in the western North Atlantic by simultaneous nonlinear inversion of hydrographic and current meter data. Deep-Sea Res., 36, 297-313.

Mix, A. C., and R. Fairbanks, 1985: North Atlantic surface-ocean control of Pleistocene deep-ocean circulation. Earth Planet. Sci. Lett., 73, 231-243.

Munk, W., and C. Wunsch, 1998: Abyssal recipes II: Energetics of tidal and wind mixing. Deep-Sea Res., 45, 1977-2010.

Press, W., S. Teukolsky, W. Vetterling, and B. Flannery, 1999: Numerical Recipes in C. Cambridge University Press, 994 pp.

Sarnthein, M., K. Winn, S. J. A. Jung, J.-C. Duplessy, L. Labeyrie, H. Erlenkeuser, and G. Ganssen, 1994: Changes in east Atlantic deepwater circulation over the last 30,000 years: Eight time slice reconstructions. Paleoceanography, 9, 209-267.

Sikes, E. L., C. R. Samson, T. P. Guilderson, and W. R. Howard, 2000: Old radiocarbon ages in the southwest Pacific Ocean during the last glacial period and deglaciation. Nature, 405, $555-559$.

Toggweiler, J. R., and B. Samuels, 1998: On the ocean's largescale circulation near the limit of no vertical mixing. J. Phys. Oceanogr., 28, 1832-1852.

_ K. Dixon, and K. Bryan, 1989: Simulations of radiocarbon in a coarse-resolution world ocean model, 1, steady state prebomb distributions. J. Geophys. Res., 94, 8217-8242.

Winguth, A., D. Archer, E. Maier-Reimer, and U. Mikolajewicz, 2000: Paleonutrient data analysis of the glacial Atlantic using an adjoint ocean general circulation model. Inverse Methods in Global Biogeochemical Cycles. Geophys. Monogr., Vol. 114, Amer. Geophys. Union, 171-183.

Wunsch, C., 1984: Acoustic tomography and other answers. A Celebration in Geophysics and Oceanography-1982; in Honor of Walter Munk on His 65th Birthday, October 19 1982, Scripps Institution of Oceanography Reference Series, Vol. 84, Scripps Institution of Oceanography, University of California, San Diego, La Jolla, CA, 47-62.

, 1996: The Ocean Circulation Inverse Problem. Cambridge University Press, 442 pp.

_ 2002 : Oceanic age and transient tracers: Analytical and numerical solutions. J. Geophys. Res., 107, 3048, doi:10.1029/ 2001JC000797.

_ 2003: Determining the paleoceanographic circulations, with emphasis on the Last Glacial Maximum. Quat. Sci. Rev., 22, 371-385.

— eral circulation of the oceans. Annu. Rev. Fluid Mech., 36, 281-313.

Yu, E., R. Francois, and M. Bacon, 1996: Similar rates of modern and last-glacial ocean thermohaline circulation inferred from radiochemical data. Nature, 379, 689-694. 